\title{
Seleção de famílias RB visando à alta produtividade e precocidade na maturação em cana-de-açúcar
}

\author{
Amanda Emanuella Rocha de Souza (1*); Francisco José de Oliveira (1); Clodoaldo José de \\ Anunciação Filho ('); Péricles de Albuquerque Melo Filho ('); Luiz José Oliveira Tavares de Melo (²); \\ José Nildo Tabosa $\left({ }^{3}\right)$
}

(') Universidade Federal Rural de Pernambuco (UFRPE), Departamento de Agronomia, Rua Dom Manoel de Medeiros s/n, Dois Irmãos, 52171-900 Recife (PE), Brasil.

(2) UFRPE, Estação Experimental de Cana-de-Açúcar do Carpina, Rua Juscelino Kubitscheck de Oliveira, s/n, Bairro Novo, Carpina

(PE), Brasil.

(3) Instituto Agronômico de Pernambuco, Av. General San Martin, 1371, Bongi, Recife (PE), Brasil.

(*) Autor correspondente: amandarocha228@gmail.com

Recebido: 13/mar./2011; Aceito: 11/ago./2011

\section{Resumo}

O objetivo deste trabalho foi avaliar dez famílias RB (República do Brasil) de irmãos germanos de cana-de-açúcar com potencial de produção e precocidade na maturação, visando à seleção de indivíduos para uso no melhoramento e comercial. O delineamento experimental adotado foi em blocos casualizados, com quatro repetições, em área agrícola localizada em Igarassu, Pernambuco, Brasil, durante o ano agrícola de 2009/2010. Foram avaliados caracteres morfoagronômicos e tecnológicos na cultura aos dez meses após o plantio. A análise multivariada foi utilizada para quantificar a divergência genética, e a distância generalizada de Mahalanobis foi empregada como medida de dissimilaridade. 0 método hierárquico de ligações médias e o método de otimização de Tocher também foram aplicados, além da estimativa das análises de trilha fenotípicas. Em vista de suas características agroindustriais superiores, as famílias FA-2, FA-3, FA-5, FA-8 e FA-9 podem ser selecionadas para produção de cana e açúcar. Os resultados relacionados à porcentagem aparente de sólidos solúveis indicaram as famílias FA-4, FA-5, FA-6 e FA-10 com tendência para maturação precoce. A variável número médio de colmos pode ser utilizada na seleção indireta de famílias mais produtivas, uma vez que teve efeito direto positivo e elevado sobre tonelada de cana por hectare.

Palavras-chave: Saccharum spp., desempenho agroindustrial, divergência genética, análise de trilha.

\section{Selection of RB sugarcane families for high productivity and early maturation}

\section{Abstract}

The aim of the present study was to evaluate ten RB (Republic of Brazil) families of full-sib sugarcane with production potential and early maturity to select individuals for use in breeding programs and for commercialization. The experimental design was in randomized blocks, with four replicates. The experiment was carried out in Igarassu, Pernambuco, Brazil, during the 2009/2010 crop season. Morphological and technological traits were evaluated ten months after planting. Multivariate analysis was used to quantify genetic divergence and Mahalanobis distance was used as the dissimilarity measure. The hierarchical mean connection method and Tocher's optimization method were applied and phenotypic path analysis was performed. Considering the agro-industrial traits, the families FA-2, FA-3, FA-5, FA-8 and FA-9 can be selected for sugar production. The results regarding the apparent percentage of soluble solids indicate that the families FA-4, FA-5, FA-6 and FA-10 have a tendency towards early maturation. The mean number of culms can be used for indirect selection of more productive families, as this variable has a substantial direct positive effect on tons of sugarcane per hectare.

Key words: Saccharum spp., agroindustrial performance, genetic divergence, path analysis. 


\section{INTRODUÇÃO}

Os programas de melhoramento genético de cana-deaçúcar têm como objetivo principal a obtenção de indivíduos superiores, com excelente potencial de produção de colmos e açúcar, para a substituição das variedades comerciais em virtude de ocorrer com o passar do tempo, um declínio nos rendimentos agrícola e industrial devido ao processo conhecido como degenerescência varietal (MAmede et al., 2002). Desta forma, o conhecimento do desempenho agroindustrial, dos desdobramentos das correlaçóes em efeitos diretos e indiretos dos caracteres, e da diversidade genética entre os genitores em programas de melhoramento de plantas, são de vital importância para os melhoristas na identificação e organização dos recursos genéticos disponíveis, visando à sua utilização para a produçáo de novas variedades promissoras.

A quantificação da diversidade genética pode ser realizada por meio de caracteres agronômicos, morfológicos, moleculares, entre outros. Diversas medidas de dissimilaridade têm sido propostas para a quantificação das distâncias entre genótipos. No entanto, a distância de Mahalanobis é a mais amplamente utilizada quando se dispóe de experimentos com repetições (CruZ e RegazzI, 2004), uma vez que esta considera as variâncias e covariâncias residuais existentes entre as características mensuradas, sendo recomendada para dados provenientes de delineamentos experimentais (AмORIM et al., 2007).

A análise de trilha (path analysis) é uma metodologia que o melhorista dispõe para entender as causas envolvidas nas associaçôes entre caracteres e decompor as correlações existentes em efeitos diretos e indiretos (CRUZ e RegazZi, 2004).

Diversos estudos relacionados ao desempenho agroindustrial, divergência genética e análise de trilha têm sido realizados em cana-de-açúcar, com o objetivo de selecionar famílias ou genótipos superiores. Alguns trabalhos reportam principalmente a importância do estudo das correlaçôes entre variáveis de destaque para a cultura da cana, via análise de trilha (Sukhchain et al., 1997; Ferreira et al., 2007; SiLva et al., 2009). Outros trabalhos citam a importância de estimar a divergência genética em canade-açúcar (Silva et al., 2011; Dutra Filho et al., 2011; SiLva et al., 2005). Contudo, estudos desta natureza ainda são necessários, visto que diferentes estruturas populacionais têm sido consideradas, pois estas são famílias oriundas de cruzamentos biparentais entre diferentes genitores, e o entendimento das consequências genéticas da manipulação dessas famílias constitui um importante papel da pesquisa na genética quantitativa da cana-de-açúcar. Este conhecimento permite identificar a natureza da ação dos genes envolvidos no controle dos caracteres quantitativos e auxilia os fitomelhoristas na seleção de bons genótipos, a fim de serem usados como genitores em programas de melhoramento.
O presente trabalho teve por objetivo avaliar famílias de irmãos germanos com potencial de produção e precocidade na maturação, visando à seleção de indivíduos para uso comercial e no melhoramento de plantas.

\section{MATERIAL E MÉTODOS}

O experimento foi desenvolvido no ano agrícola 2009/2010, em cana-soca, no município de Igarassu, Litoral Norte da Mata de Pernambuco (70 50' 00"S, 34º 54'30"W e 19,0 m de altitude), em Latossolo VermelhoAmarelo Distrófico textura argilosa, segundo a caracterização de Koffler et al. (1986).

Odelineamento experimental utilizado foi em blocos ao acaso com quatro repetições, e dez famílias de cana-de-açúcar oriundas dos cruzamentos biparentais: FA-1 (RB92579 x RB855350); FA-2 (RB867515 x RB953114); FA-3 (RB83102 x RB855035); FA-4 (RB92606 x RB92579); FA-5 (RB83102 x RB855595); FA-6 (RB855035 x RB855595); FA-7 (RB855025 x RB863129); FA-8 (RB867515 x RB95546); FA-9 (RB946903 x RB863129); FA-10 (CP88-1540 x RB92579). Basicamente, os programas de melhoramento genético de cana-de-açúcar têm usado o índice de seleção nas progênies, pesquisa em artigos publicados de divergência genética para exploração da heterose e disponibilidade de sementes, como critérios para identificação de cruzamentos e para a escolha das famílias nos testes em experimentos.

Cada parcela experimental foi representada por dois sulcos de 5,0 m de comprimento, com espaçamento entre sulcos de 1,20 m, e 1,00 m entre clones dentro de sulcos. A colheita da cana-soca foi realizada em outubro de 2010, aos dez meses após o plantio.

Para efeito de tratamento, dez colmos foram aleatoriamente amostrados em cada parcela para a avaliação dos seguintes caracteres: (1) diâmetro médio de colmo (DMC), mensurado com o auxílio de um paquímetro no terceiro internódio da base e na porção mediana do colmo, medido em milímetros $(\mathrm{mm})$ e convertido para centímetros $(\mathrm{cm})$; (2) altura média de colmo (AMC), determinada com o auxílio de uma trena, medida em centímetros a partir da base do colmo até o primeiro "dewlap" visível (inserção da folha +1 ), de acordo com classificação descrita por Kuijper (Dillewijn, 1952); (3) número médio de colmos (NMC) expresso em unidade, obtido pela contagem do número total de colmos em uma parcela experimental, sendo posteriormente calculado o número de colmos por metro linear; (4) massa média de colmo (MMC), obtido pela pesagem, em quilograma, de todos os colmos da parcela experimental, sendo a massa total dividida pelo número de colmos presentes nas respectivas parcelas experimentais; (5) toneladas de colmos por hectare (TCH) calculada por meio da transformação da massa da parcela em tonelada por hectare; (6) toneladas de pol por hectare 
(TPH), obtido pela multiplicação do TCH pelo pol na cana (PC); (7) toneladas de sólidos solúveis por hectare $(\mathrm{TBH})$, calculado através do produto entre TCH e sólidos solúveis. $\mathrm{Na}$ época da colheita, foram amostrados dez colmos para determinação da porcentagem de fibra na cana (FIB), porcentagem aparente de sólidos solúveis, pol na cana (PC), pureza na cana (PUR) e açúcar total recuperável (ATR), segundo Fernandes (2003). Durante o manejo do experimento foram realizados os tratos culturais exigidos para a cultura.

A análise de variância foi realizada para todos os caracteres individualmente e as médias foram agrupadas pelo teste de Sсотт е Клотт (1974), considerando 5\% de probabilidade $(\mathrm{p}<0,05)$. A análise multivariada foi utilizada para avaliar a divergência genética entre as famílias utilizando como medida de dissimilaridade a distância generalizada de Mahalanobis. O método de Tocher (RAo, 1952) foi empregado como técnica de agrupamento por otimizaçáo, cujo princípio básico é manter a homogeneidade dentro e heterogeneidade entre os grupos formados. Em seguida, para a construção do dendrograma foi utilizado o método hierárquico UPGMA (Unweighted Pair Group Method using Arithmetical Averages), desenvolvido por Sokal e Michener (1958), com base na Distância Generalizada de Mahalanobis (Mahalanobis, 1936), cujos resultados foram utilizados para comparação dos padróes de agrupamento produzidos pelos dois diferentes métodos (UPGMA e Tocher). A contribuição relativa dos caracteres avaliados para a divergência entre as famílias foi obtida pela metodologia proposta por SINGH (1981).

Desdobramentos das correlações entre os caracteres, em efeitos diretos e indiretos, foram realizados por meio da análise de trilha desenvolvida por WRight (1921). Antes da execução da análise de trilha, foi realizado o diagnóstico do grau de multicolinearidade da matriz singular X'X, estabelecido com base no número de condição (NC), que corresponde à relação entre o maior e o menor autovalor da matriz. A análise da multicolinearidade e todas as outras análises realizadas no presente trabalho foram executadas pelo programa Genes (CRUZ, 2007).

\section{RESULTADOS E DISCUSSÃO}

Há diferenças significativas entre as famílias de cana-deaçúcar, a 5\% de probabilidade pelo teste $\mathrm{F}$, para as variáveis altura média de colmos (AMC), toneladas de cana por hectare $(\mathrm{TCH})$, toneladas de açúcar provável por hectare $(\mathrm{TPH})$ e toneladas de sólidos solúveis por hectare (TBH), indicando a existência de variabilidade, com possibilidade de melhoramento desses caracteres (Tabela 1). Para as características porcentagem aparente de sólidos solúveis, pureza na cana (PUR) e açúcar total recuperável (ATR) houve diferença significativa a $1 \%$ de probabilidade.

$\mathrm{O}$ coeficiente de variação experimental $\left(\mathrm{CV}_{\mathrm{E}}\right)$ oscilou entre $1,41 \%$ e $24,87 \%$, valores considerados de baixo a médio, evidenciando boa precisão experimental e, consequentemente, eficaz nas determinaçōes das características DMC, AMC, PC, FIB, PUR e ATR, sendo satisfatórios para os caracteres MMC, TCH, TPH e TBH, conforme tabela 1, podendo ser aceitável para NMC.

No número médio de colmos (NMC) não houve diferença significativa entre as famílias, cujo valor médio foi de 8,0 colmos por metro linear. De acordo com BARBosa e Silveira (2000), na fase de seleção T1, deve-se selecionar plantas com mais de seis colmos. Assim, todas as famílias foram promissoras para seleção com base neste caráter. Pedrozo et al. (2008), concordando com essas afirmaçóes,

Tabela 1. Agrupamento de médias das variáveis número médio de colmos (NMC), diâmetro médio dos colmos (DMC), altura média dos colmos (AMC), massa média dos colmos (MMC), toneladas de cana por hectare (TCH), toneladas de pol por hectare (TPH), toneladas de sólidos solúveis por hectare (TBH), pol na cana (PC), sólidos solúveis, porcentagem de fibra na cana (FIB), pureza na cana (PUR) e açúcar total recuperável (ATR)

\begin{tabular}{|c|c|c|c|c|c|c|c|c|c|c|c|c|}
\hline Famílias & $\begin{array}{l}\text { NMC } \\
\text { (unid.) }\end{array}$ & $\begin{array}{l}\text { DMC } \\
(\mathrm{cm})\end{array}$ & $\begin{array}{l}\text { AMC } \\
(m)\end{array}$ & $\begin{array}{l}\text { MMC } \\
\text { (kg) }\end{array}$ & $\begin{array}{c}\text { TCH } \\
\left(\mathrm{t} \mathrm{ha}^{-1}\right)\end{array}$ & $\begin{array}{c}\text { TPH } \\
\left(t \mathrm{ha}^{-1}\right)\end{array}$ & 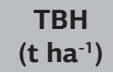 & $\begin{array}{l}\text { PC } \\
(\%)\end{array}$ & $\begin{array}{c}\text { Sólidos } \\
\text { solúveis (\%) }\end{array}$ & $\begin{array}{l}\text { FIB } \\
(\%)\end{array}$ & $\begin{array}{l}\text { PUR } \\
\text { (\%) }\end{array}$ & $\begin{array}{c}\text { ATR } \\
\left(\mathrm{kg} \mathrm{t}^{-1}\right)\end{array}$ \\
\hline FA-1 & $7,00 \mathrm{a}$ & $2,41 \mathrm{a}$ & $2,64 \mathrm{a}$ & $0,92 \mathrm{a}$ & $44,70 \mathrm{~b}$ & $6,40 \mathrm{~b}$ & $9,05 \mathrm{~b}$ & $14,31 \mathrm{a}$ & 20,23 b & 12,39 a & $85,22 \mathrm{a}$ & $43,08 \mathrm{~b}$ \\
\hline FA-2 & $8,05 \mathrm{a}$ & $2,33 a$ & $2,35 b$ & $1,01 \mathrm{a}$ & $55,47 \mathrm{a}$ & $7,45 \mathrm{a}$ & $10,82 \mathrm{a}$ & $13,44 \mathrm{a}$ & 19,52 c & $13,33 \mathrm{a}$ & 82,87 b & $137,01 \mathrm{c}$ \\
\hline FA-3 & $8,62 \mathrm{a}$ & $2,35 \mathrm{a}$ & $2,74 a$ & $1,07 \mathrm{a}$ & $63,98 \mathrm{a}$ & $8,44 a$ & $12,45 \mathrm{a}$ & $13,19 \mathrm{a}$ & $19,46 \mathrm{c}$ & $13,89 a$ & 80,19 c & $132,18 \mathrm{~d}$ \\
\hline FA-4 & $6,82 \mathrm{a}$ & $2,37 \mathrm{a}$ & $2,60 \mathrm{a}$ & $0,92 \mathrm{a}$ & $43,14 b$ & $6,18 b$ & $9,08 \mathrm{~b}$ & $14,49 a$ & $21,03 \mathrm{a}$ & $13,49 a$ & $84,42 \mathrm{a}$ & $147,60 \mathrm{a}$ \\
\hline FA-5 & $9,87 \mathrm{a}$ & $2,18 \mathrm{a}$ & $2,40 \mathrm{~b}$ & $0,88 \mathrm{a}$ & 59,89 a & $7,88 \mathrm{a}$ & $12,69 \mathrm{a}$ & $13,23 \mathrm{a}$ & $21,16 \mathrm{a}$ & $13,28 \mathrm{a}$ & $82,13 b$ & $130,90 \mathrm{~d}$ \\
\hline FA-6 & $7,55 \mathrm{a}$ & $2,17 \mathrm{a}$ & $2,42 \mathrm{~b}$ & $0,92 \mathrm{a}$ & $47,57 \mathrm{~b}$ & $6,26 \mathrm{~b}$ & 9,86 b & $13,20 \mathrm{a}$ & $20,75 a$ & $13,72 \mathrm{a}$ & $80,06 \mathrm{c}$ & $137,15 \mathrm{c}$ \\
\hline FA-7 & $5,90 \mathrm{a}$ & $2,36 \mathrm{a}$ & $2,64 a$ & $0,95 \mathrm{a}$ & $38,37 \mathrm{~b}$ & $5,11 \mathrm{~b}$ & $7,78 \mathrm{~b}$ & $13,27 \mathrm{a}$ & $0,28 \mathrm{~b}$ & $12,98 \mathrm{a}$ & $77,49 \mathrm{~d}$ & $138,41 \mathrm{c}$ \\
\hline$F A-8$ & $9,07 \mathrm{a}$ & $2,39 a$ & $2,39 \mathrm{~b}$ & $0,95 \mathrm{a}$ & $58,85 \mathrm{a}$ & $8,01 \mathrm{a}$ & $11,54 \mathrm{a}$ & $13,62 \mathrm{a}$ & 19,62 c & $13,04 \mathrm{a}$ & $81,41 \mathrm{c}$ & $137,63 \mathrm{c}$ \\
\hline FA-9 & $9,12 \mathrm{a}$ & $2,43 a$ & $2,71 \mathrm{a}$ & $1,07 \mathrm{a}$ & $67,10 a$ & $8,92 \mathrm{a}$ & $13,00 \mathrm{a}$ & $13,26 a$ & $19,38 \mathrm{c}$ & $12,82 \mathrm{a}$ & $83,76 \mathrm{a}$ & $131,96 \mathrm{~d}$ \\
\hline FA-10 & $7,97 \mathrm{a}$ & $2,40 a$ & $2,61 \mathrm{a}$ & $0,92 \mathrm{a}$ & $50,35 \mathrm{~b}$ & $7,07 \mathrm{~b}$ & $10,68 \mathrm{a}$ & $14,21 \mathrm{a}$ & $21,27 a$ & $12,62 \mathrm{a}$ & $82,63 \mathrm{~b}$ & $148,66 \mathrm{a}$ \\
\hline Média & 8,00 & 2,34 & 2,55 & 0,96 & 52,94 & 7,17 & 10,70 & 13,63 & 20,27 & 13,16 & 82,02 & 138,46 \\
\hline QM & $5,92^{\text {ns }}$ & $0,03^{\text {ns }}$ & $0,085^{*}$ & $0,018^{\text {ns }}$ & $366,13^{*}$ & $5,61^{*}$ & $12,27^{*}$ & $1,05^{\mathrm{ns}}$ & $2,24^{* *}$ & $0,91^{\mathrm{ns}}$ & $21,45^{* *}$ & $156,53^{* *}$ \\
\hline$C V_{E}(\%)$ & 24,87 & 7,65 & 7,44 & 13,67 & 20,51 & 20,12 & 20,68 & 6,20 & 1,63 & 6,89 & 1,41 & 2,10 \\
\hline
\end{tabular}

Médias seguidas pela mesma letra, nas colunas, pertencem ao mesmo grupo pelo teste de agrupamento de Scott e Knott (1974) a 5\% de probabilidade; *, **: Significativo a 5\%

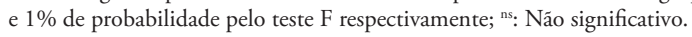


alegam ainda que, em média, nos genótipos com menos de cinco colmos há tendência de ser menos produtivos, e não devem ser selecionados nem mesmo quando as demais características avaliadas forem favoráveis.

Para a variável altura média de colmos (AMC) as famílias FA-1, FA-3, FA-4, FA-7, FA-9 e FA-10 diferiram das famílias FA-2, FA-5, FA-6 e FA-8. A média verificada foi de $2,55 \mathrm{~m}$, variando de $2,35 \mathrm{~m}$ (FA-2) a 2,74 m (FA-3), valores superiores aos obtidos por SiLVA (2008), que ao avaliar doze genótipos de cana-de-açúcar, aos doze meses após o plantio, observou média de 2,20 $\mathrm{m}$ de altura de colmos.

Em relação às variáveis TCH e TPH, observa-se a existência de dois grupos. Quanto à TCH, a média verificada da foi de 52,94 $\mathrm{t} \mathrm{ha}^{-1}$, cujas famílias FA-2, FA-3, FA-5, FA-8 e FA-9 obtiveram rendimentos, respectivamente, de 55,$47 ; 63,98 ; 59,89 ; 58,85$ e $67,10 \mathrm{t} \mathrm{ha}^{-1}$, superiores às demais famílias. Na variável TPH, a média de tonelada de açúcar por hectare situou-se em 7,17, e as famílias com as maiores produtividades de açúcar por hectare foram FA-2, FA-3, FA-5, FA-8 e FA-9 com 7,45; 8,44; 7,88; 8,01 e $8,92 \mathrm{t} \mathrm{ha}^{-1}$ pol respectivamente. Este parâmetro foi conferido pela maior produtividade de colmos $\left(\mathrm{t} \mathrm{ha}^{-1}\right)$ dessas famílias. Mero et al. (2006), avaliando dezesseis genótipos de cana-de-açúcar, observaram resultados semelhantes para média geral do caráter TCH $\left(65,72 \mathrm{t} \mathrm{ha}^{-1}\right)$ e TPH $\left(8,12 \mathrm{t} \mathrm{ha}^{-1}\right)$.

Para a variável TBH, observou-se que as famílias FA-2, FA-3, FA-5, FA-8, FA-9 e FA-10 diferiram das famílias FA-1, FA-4, FA-6 e FA-7, porém, não diferindo entre si. A média verificada, aos dez meses de idade, foi de 10,70 toneladas por hectare de sólidos solúveis, variando entre 7,78 e 13,00 tha hólidos solúveis, para as famílias FA-7 e FA-9, respectivamente. BAsTos (2003), aos doze meses após o plantio, obteve uma média de $21,23 \mathrm{t} \mathrm{ha}^{-1}$ sólidos solúveis para a variável TBH.

Dentre todas as variáveis, PUR e ATR foram as que formaram quatro grupos. As famílias FA-1, FA-4 e FA-9 proporcionaram valores estatisticamente superiores para pureza na cana (PUR) em relação às demais famílias. A média de PUR foi igual a $82,02 \%$, e o maior valor verificado foi para FA-1 $(85,22 \%)$ e o menor para FA-7 (77,49\%). Melo et al. (2006), avaliando dezesseis genótipos de cana-de-açúcar constataram resultados semelhantes para média geral do caráter pureza (86\%). Quanto à variável ATR, a média obtida foi de $138,46 \mathrm{~kg} \mathrm{t}^{-1}$, variando entre $130,90 \mathrm{~kg} \mathrm{t}^{-1}$ e $148,66 \mathrm{~kg} \mathrm{t}^{-1}$, respectivamente, para as famílias FA-5 e FA-10. Resultados similares foram obtidos por Dutra Filho (2011) que, avaliando seis genótipos obteve média de $92,93 \mathrm{~kg} \mathrm{t}^{-1}$ de ATR.

Pode-se verificar na tabela 1 três grupos distintos para porcentagem aparente de sólidos solúveis. As famílias FA-4, FA-5, FA-6 e FA-10 diferiram dos demais grupos. Este resultado revela que essas famílias tendem a ser mais precoce na maturação, visto que atingiram um percentual de sólidos solúveis desejável mais cedo quando comparadas a outras famílias. A média de sólidos solúveis, aos dez meses após plantio em cana-soca, ficou em torno de $20,27 \%$, variando entre $19,38 \%$ (FA-9) e $21,27 \%$ (FA10). Melo et al. (2006), estudando doze genótipos e quatro variedades- padráo observaram média de sólidos solúveis ao redor de $17,18 \%$, sendo inferior à constatada neste trabalho.

Os valores das dissimilaridades entre famílias, geradas pela Distância Generalizada de Mahalonobis, estáo apresentados na tabela 2. Entre os dez pares com maior dissimilaridade através da análise das Distâncias $\left(\mathrm{D}^{2}\right)$, foi possível identificar as combinaçóes FA-3 e FA-4 $(146,75)$, FA-3 e FA-5 (130,02), FA-3 e FA-10 (126,58), FA-4 e FA-9 (120,73), FA-5 e FA-7 (117,06), FA-3 e FA-1 $(116,54)$, FA-9 e FA-10 $(115,28)$, FA-4 e FA-7 $(107,35)$, FA-5 e FA-9 $(102,24)$ e FA-1 e FA-7 $(101,86)$ como os pares de famílias mais divergentes.

Observa-se que as famílias mais distantes, FA-3 (RB83102 X RB855035) e FA-4 (RB92606 X RB92579) não são aparentadas, confirmando assim, o que se esperava, pois quanto mais diferentes os materiais, presumia-se maior divergência genética entre eles.

Tabela 2. Estimativas das distâncias entre as dez famílias (FA) de cana-de-açúcar quantificadas pelo método das distâncias generalizadas de Mahalanobis $\left(\mathrm{D}^{2}\right)$

\begin{tabular}{|c|c|c|c|c|c|c|c|c|c|c|c|}
\hline \multirow{2}{*}{ FA } & \multicolumn{11}{|c|}{ Distâncias entre famílias } \\
\hline & 2 & 3 & 4 & 5 & 6 & 7 & 8 & 9 & 10 & $D^{2}>$ & $D^{2}<$ \\
\hline FA-1 & 24,65 & 116,54 & 23,19 & 58,74 & 42,32 & 101,86 & 44,66 & 62,53 & 32,67 & 116,54 & 23,19 \\
\hline FA-2 & 0 & 59,91 & 65,95 & 63,88 & 37,50 & 72,53 & 8,82 & 23,69 & 68,87 & 72,53 & 8,82 \\
\hline FA-3 & & 0 & 146,75 & 130,02 & 56,59 & 30,76 & 29,55 & 36,51 & 126,58 & 146,75 & 29,55 \\
\hline $\mathrm{FA}-4$ & & & 0 & 60,36 & 39,52 & 107,35 & 79,39 & 120,73 & 8,10 & 146,75 & 8,10 \\
\hline FA-5 & & & & 0 & 33,85 & 117,06 & 75,24 & 102,24 & 69,11 & 130,02 & 33,85 \\
\hline FA-6 & & & & & 0 & 30,91 & 30,08 & 66,60 & 32,14 & 66,60 & 30,08 \\
\hline FA-7 & & & & & & 0 & 39,79 & 83,57 & 78,21 & 117,06 & 30,76 \\
\hline FA-8 & & & & & & & 0 & 19,93 & 68,69 & 79,39 & 8,82 \\
\hline FA-9 & & & & & & & & 0 & 115,28 & 120,73 & 19,93 \\
\hline FA-10 & & & & & & & & & 0 & 126,58 & 8,10 \\
\hline
\end{tabular}

$\mathrm{D}^{2}$ : distância de Mahalanobis; $\mathrm{D}^{2}>$ : maior distância de Mahalanobis; $\mathrm{D}^{2}<$ : menor distância de Mahalanobis. 
As distâncias entre os pares de famílias, considerando os doze caracteres agroindustriais, indicaram que os pares mais similares foram: FA-4 (RB92606 X RB92579) e FA-10 (CP881540 X RB92579) e FA-2 (RB867515 X RB953114) e FA-8 (RB867515 X RB95546). Verifica-se, portanto, que esses materiais são aparentados, cujas famílias FA-4 e FA-10 possuem genitor masculino em comum (RB92579) e as famílias FA-2 e FA-8 (RB867515), o genitor feminino em comum.

Cruz e Regazzi (2004) sugerem o não envolvimento de indivíduos de mesmo padrão de dissimilaridade nos cruzamentos, de modo que não restrinja a variabilidade genética e, assim, evitar reflexos negativos nos ganhos a serem obtidos pela seleção. Conforme relatado por ABREU et al. (1999) e CARPENTIERI-Pípolo et al., (2000), as melhores combinações híbridas a serem testadas em um programa de melhoramento, devem envolver parentais tanto divergentes como de elevado desempenho médio.

Os caracteres que mais contribuíram para a divergência genética pelo método de SINGH (1981), para as dez famílias de cana-de-açúcar, foram TCH e TBH, com valores de contribuição de $41,96 \%$ e $23,99 \%$ respectivamente, totalizando $65,95 \%$ (Tabela 3). Similarmente, Silva et al. (2011) verificou que TCH foi um dos principais determinantes na quantificação da divergência genética.

Quanto aos coeficientes de variação genética, observase que os caracteres TCH $(14,88), \mathrm{TBH}(12,69)$ e TPH $(13,09)$ tiveram valores mais altos, acima de $10 \%$. Segundo Oliveira et al. (2005) e Bastos et al. (2007), valores acima de $10 \%$ já indicam haver presença de variabilidade genética com possibilidade de seleção efetiva entre as famílias.

Tabela 3. Importância relativa de doze caracteres agroindustriais para estudo da diversidade genética entre dez famílias de cana-deaçúcar, segundo critério de SINGH (1981) e parâmetros associados a essas características

\begin{tabular}{|c|c|c|c|c|c|}
\hline Caracteres & S. $j$ & $\begin{array}{l}\text { S. } j \\
(\%)\end{array}$ & $\begin{array}{l}\text { Herdabilidade } \\
\qquad\left(\mathrm{h}_{\mathrm{a}}{ }_{\mathrm{a}}\right)\end{array}$ & $C V g$ & $\begin{array}{l}\mathrm{CVg} / \\
\mathrm{CVe}\end{array}$ \\
\hline NMC & 185,56 & 2,63 & 33,18 & 8,76 & 0,35 \\
\hline DMC & 32,12 & 0,45 & 1,13 & 0,41 & 0,05 \\
\hline AMC & 143,65 & 2,04 & 57,56 & 4,33 & 0,58 \\
\hline MMC & 320,83 & 4,55 & 2,84 & 1,17 & 0,08 \\
\hline $\mathrm{TCH}$ & 2958,63 & 41,96 & 67,79 & 14,88 & 0,72 \\
\hline TPH & 50,96 & 0,72 & 62,88 & 13,09 & 0,65 \\
\hline $\mathrm{TBH}$ & 1691,15 & 23,99 & 60,10 & 12,69 & 0,61 \\
\hline FIB & 69,74 & 0,99 & 9,34 & 1,10 & 0,16 \\
\hline PC & 40,51 & 0,57 & 32,05 & 2,13 & 0,34 \\
\hline PUR & 902,46 & 12,80 & 93,76 & 2,73 & 1,94 \\
\hline ATR & 589,69 & 8,36 & 94,57 & 4,39 & 2,09 \\
\hline $\begin{array}{l}\text { SÓLIDOS } \\
\text { SOLÚVEIS }\end{array}$ & 64,86 & 0,92 & 95,10 & 3,60 & 2,20 \\
\hline
\end{tabular}

S.j: contribuição da variável $x$ para o valor da distância de Mahalanobis entre os genótipos $i$ e $i$; CVg: coeficiente de variaçăo genética; CVe: coeficiente de variaçăo ambiental; $\mathrm{h}^{2}$ : herdabilidade no sentido amplo; número médio de colmos (NMC); diâmetro médio dos colmos (DMC); altura média dos colmos (AMC); massa média dos colmos (MMC); toneladas de cana por hectare (TCH); toneladas de pol por hectare (TPH); toneladas de sólidos solúveis por hectare (TBH); pol na cana (PC); sólidos solúveis; porcentagem de fibra na cana (FIB); pureza na cana (PUR); açúcar total recuperável (ATR).
A razão entre o coeficiente de variação genética e o coeficiente de variação ambiental $\left(\mathrm{CV}_{\mathrm{G}} / \mathrm{CV}_{\mathrm{E}}\right)$ observada foi superior à unidade para os caracteres PUR $(1,94), \mathrm{BC}$ $(2,20)$ e ATR $(2,09)$, refletindo a condição favorável para seleção destes caracteres (VENCOsvKY, 1987). A relação $\mathrm{CV}_{\mathrm{G}} / \mathrm{CV}_{\mathrm{E}}$ de magnitude superior a 1,0 mostra condiçôes adequadas ao melhoramento, o que foi observado por SiLva et al., (2011), nos caracteres NC, MMC, TCH, PC e $\mathrm{BC}$, indicando que o componente genético foi mais importante que o ambiental.

Observa-se que as herdabilidades médias proporcionaram valores considerados entre médios e altos para os caracteres AMC (57,56\%), TCH (67,79\%), TPH $(62,89 \%)$, TBH $(60,10 \%)$, PUR $(93,76 \%)$, BC $(95,10 \%)$ e ATR (94,57\%), indicando possibilidade de sucesso na seleção, visto que há predominância do componente genético atuando nestes caracteres. SANTANA (2010), avaliando parâmetros genéticos em caracteres de cana-de-açúcar verificou grande amplitude de resultados para as estimativas de herdabilidade. Esta grande faixa de variação pode ser devido a vários fatores, tais como, problemas de amostragem, às diferenças existentes entre populações e às diferenças de ambiente (RamalHo et al., 1993).

Houve a formação de quatro grupos pelo método de otimização de Tocher (Tabela 4), sendo os dois maiores grupos formados por três famílias (30\% do total em cada grupo) e outros dois grupos com duas famílias ( $20 \%$ do total em cada grupo). Esse padrão de distribuição reforça a variabilidade entre as famílias constatadas na análise de variância e, consequentemente, em grande divergência genética. As famílias FA-4 (RB92606 X RB92579), FA-10 (CP881540 X RB92579) e FA-1 (RB92579 X RB855330) agrupadas no grupo I possuem a mesma constituição genética materna ou paterna (RB92579). As famílias FA-2 (RB867515 X RB953114) e FA-8 (RB867515 X RB95546), reunidas no grupo II possuem o progenitor feminino em comum (RB867515). As famílias FA-5 (RB83102 X RB855595) e FA-6 (RB855035 X RB855595), agrupadas no grupo IV possuem a mesma constituição paterna (RB855595).

Com base nos resultados observados pelo agrupamento de Tocher e no desempenho das famílias avaliadas, poderiam ser indicados cruzamentos entre as famílias mais divergentes e mais produtivas, pois segundo CARPENTIERI-PíPOLO et al. (2000), a identificação de genótipos com base somente na

Tabela 4. Formação dos grupos de dissimilaridade pelo método de Tocher a partir das distâncias de Mahalanobis, estimadas para as dez famílias RB de cana-de-açúcar, avaliados para doze caracteres agroindustriais

\begin{tabular}{|lcc|} 
Grupos & Famílias & $\%$ \\
\hline I & 4,10 e 1 & 30 \\
II & 2,8 e 9 & 30 \\
III & 3 e 7 & 20 \\
IV & 5 e 6 & 20 \\
\hline
\end{tabular}


divergência sem considerar seu desempenho, pode não ser boa alternativa, sendo recomendado o uso de indivíduos divergentes com características agronômicas importantes. Assim, considerando o desempenho e a divergência, recomendam-se os cruzamentos entre as famílias FA-10, FA-2, FA-3 e FA-5, que pertencem a grupos distintos, por serem bastante divergentes (Tabela 2) e os mais produtivos, de acordo com o caráter TBH, aliados aos caracteres TCH e TPH (Tabela 1). SiLva et al. (2011), avaliando a divergência genética e o desempenho agroindustrial de genótipos de cana-de-açúcar, recomendaram alguns cruzamentos entre os genótipos mais divergentes e agronomicamente superiores, para fins de melhoramento genético, podendo ser promissores para a geração de novas combinaçôes de alelos favoráveis à obtençâo de indivíduos geneticamente superiores com excelente potencial heterótico.

De acordo com o dendograma obtido pelo método de agrupamento hierárquico UPGMA (Figura 1), as famílias foram reunidas em quatro grupos, considerando linha de corte a aproximadamente $42 \%$ da distância genética relativa, conforme o critério mencionado por Cruz e Carneiro (2006), no qual as delimitações podem ser estabelecidas por um exame visual do dendograma, em que se avaliam pontos de alta mudança de nível, tomando-os em geral como delimitadores do número de genótipos para determinado grupo.

Tanto no método UPGMA quanto no método de agrupamento de Tocher, as dez famílias de cana-de-açúcar foram agrupadas de forma semelhante, com base em suas dissimilaridades. Assim, as dez famílias de cana-de-açúcar foram distribuídas em quatro grupos em ambos os métodos. O grupo I englobou as famílias FA-4, FA-10 e FA-1 correspondendo ao grupo I do método de Tocher; o grupo II (FA-5 e FA-6) corresponde ao grupo IV do método de Tocher; o grupo III (FA-2, FA-8 e FA-9) corresponde ao grupo II e o grupo IV (FA-3 e FA-7) corresponde ao grupo III do método de otimizaçáo de Tocher. Estes resultados similares obtidos pelos dois métodos de agrupamento reforçam as possíveis recomendações de cruzamento entre as famílias avaliadas.

Dutra Filho et al. (2011), utilizando técnicas multivariadas para avaliar a divergência genética em seis progênies de cana-de-açúcar, verificaram pelo método de otimização de Tocher, a formação de quatro grupos distintos.

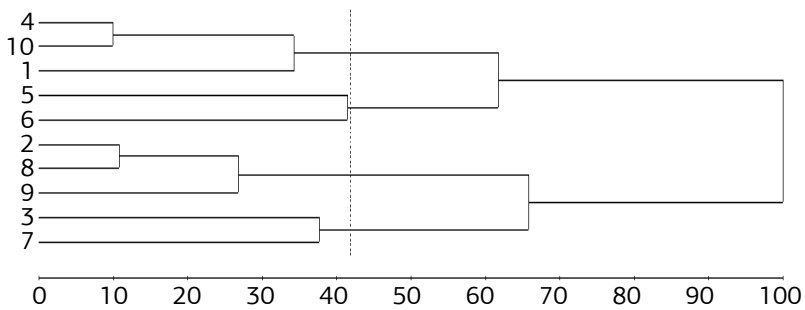

Figura 1. Dendograma para o padrão de dissimilaridade, estabelecido pelo método UPGMA, com base na distância de Mahalanobis $\left(\mathrm{D}_{\mathrm{i},}{ }^{2}\right)$, para as dez famílias de cana-de-açúcar.
O diagnóstico de multicolinearidade das análises de trilha deste trabalho resultou em fraca colinearidade. Os coeficientes de trilha fenotípicos explicaram bem as variaçôes em $\mathrm{TCH}$, como indica o alto valor de determinaçáo do modelo $\left(\mathrm{R}^{2}=0,8962\right)$ e pelo baixo efeito residual $(0,3222)$, o que reflete a excelente contribuição das variáveis do modelo para a produção de colmos (Tabela 5). A maior contribuição para a variável TCH $(0,9851)$ ocorreu com componente de produção NMC, evidenciando a possibilidade de obterem ganhos significativos por meio da seleção indireta para TCH via NMC. A definição de caracteres que auxiliam na seleção indireta para produtividade é imprescindível nas etapas iniciais de um programa de melhoramento de cana-de-açúcar (SiLva et al., 2009).

Neste contexto, uma segunda análise de trilha foi realizada, definindo-se um modelo de regressão em que MMC é dado como a variável principal e AMC e DMC as variáveis explicativas (Tabela 6). Os efeitos diretos de AMC e DMC

Tabela 5. Análise de trilha fenotípica dos componentes de produçấo número médio de colmos (NMC), altura média de colmos (AMC) e diâmetro médio de colmos (DMC) sobre a variável principal tonelada de cana por hectare $(\mathrm{TCH})$

\begin{tabular}{lr}
\hline Variáveis & Fenotípica \\
\hline NMC & \\
\hline Efeito direto sobre TCH & 0,9851 \\
\hline Efeito indireto via DMC & $-0,0232$ \\
\hline Efeito indireto via AMC & $-0,0534$ \\
\hline Total & 0,9085 \\
\hline DMC & \\
\hline Efeito direto sobre TCH & 0,1109 \\
\hline Efeito indireto via NMC & $-0,2063$ \\
\hline Efeito indireto via AMC & 0,1160 \\
\hline Total & 0,0207 \\
\hline AMC & \\
\hline Efeito direto sobre TCH & 0,1966 \\
\hline Efeito indireto via NMC & $-0,2677$ \\
\hline Efeito indireto via DMC & 0,0655 \\
\hline Total & $-0,0056$ \\
\hline Coeficiente de determinação $\left(\mathrm{R}^{2}\right)$ & 0,8962 \\
\hline Efeito da variável residual & 0,3222 \\
\hline
\end{tabular}

Tabela 6. Análise de trilha fenotípica dos componentes de produção altura de colmos (AMC) e diâmetro de colmos (DMC) sobre massa média de colmos (MMC)

\begin{tabular}{lc|}
\hline Variáveis & Fenotípica \\
\hline AMC & \\
\hline Efeito direto sobre MMC & 0,2940 \\
\hline Efeito indireto via DMC & 0,1406 \\
\hline Total & 0,4346 \\
\hline DMC & \\
\hline Efeito direto sobre MMC & 0,2385 \\
\hline Efeito indireto via AMC & 0,1733 \\
\hline Total & 0,4118 \\
\hline Coeficiente de determinação $\left(\mathrm{R}^{2}\right)$ & 0,2260 \\
\hline Efeito da variável residual & 0,8798 \\
\hline
\end{tabular}


sobre MMC foram pequenos $(0,2940$ e 0,2385$)$. FerReIrA et al. (2007) obtiveram efeito direto fenotípico de AMC de maior magnitude quando comparado a DMC.

A variável TCH proporcionou efeitos diretos altos sobre TPH (0,9830, altamente correlacionadas) (Tabela 7). Esse efeito de elevada magnitude entre TPH e TCH evidencia a importância desse caráter em programas de melhoramento, visando à elevaçấo da produtividade de açúcar. A variável PC propiciou efeito direto pequeno e positivo sobre TPH $(0,1339)$. Os coeficientes de determinação $\left(R^{2}\right)$ fenotípico igual a 0,8572 , e o baixo efeito

Tabela 7. Análise de trilha fenotípica dos componentes toneladas de cana por hectare (TCH) e pol na cana (PC) sobre a produtividade em açúcar (TPH)

\begin{tabular}{lc} 
Variáveis & Fenotípica \\
\hline TCH & \\
\hline Efeito direto sobre TPH & 0,9830 \\
Efeito indireto via PC & $-0,0646$ \\
\hline Total & 0,9184 \\
PC & \\
\hline Efeito direto sobre TPH & 0,1339 \\
Efeito indireto via TCH & $-0,4742$ \\
\hline Total & $-0,3403$ \\
Coeficiente de determinação $\left(\mathrm{R}^{2}\right)$ & 0,8572 \\
\hline Efeito da variável residual & 0,3779 \\
\hline
\end{tabular}

Tabela 8. Análise de trilha fenotípica dos componentes tecnológicos sólidos solúveis, fibra \% cana (FIB), pureza na cana (PUR) e açúcar total recuperável (ATR) sobre pol na cana (PC)

\begin{tabular}{|lc|}
\hline Variáveis & Fenotípica \\
\hline Sólidos Solúveis & \\
\hline Efeito direto sobre PC & $-0,0043$ \\
\hline Efeito indireto via FIB & 0,0002 \\
\hline Efeito indireto via PUR & 0,0279 \\
\hline Efeito indireto via ATR & 0,3997 \\
\hline Total & 0,4236 \\
\hline FIB & \\
\hline Efeito direto sobre PC & $-0,0033$ \\
\hline Efeito indireto via Sólidos Solúveis & 0,0003 \\
\hline Efeito indireto via PUR & $-0,1596$ \\
\hline Efeito indireto via ATR & $-0,2919$ \\
\hline Total & $-0,4546$ \\
\hline PUR & \\
\hline Efeito direto sobre PC & 0,3961 \\
\hline Efeito indireto via Sólidos Solúveis & $-0,0003$ \\
\hline Efeito indireto via FIB & 0,0013 \\
\hline Efeito indireto via ATR & 0,2595 \\
\hline Total & 0,6567 \\
\hline ATR & \\
\hline Efeito direto sobre PC & 0,7631 \\
\hline Efeito indireto via Sólidos Solúveis & $-0,0022$ \\
\hline Efeito indireto via FIB & 0,0013 \\
\hline Efeito indireto via PUR & 0,1347 \\
\hline Total & 0,8969 \\
\hline Coeficiente de determinação (R²) & 0,9443 \\
\hline Efeito da variável residual & 0,2360 \\
\hline
\end{tabular}

residual de 0,3779 , representa satisfatoriamente a contribuição de TCH para explicar a produtividade de açúcar. REDDY e REDDI (1986) também observaram superioridade do efeito direto da produtividade de cana para explicar a produtividade de açúcar.

A variável PC proporcionou a maior estimativa de efeito direto sobre ATR $(0,7631)$, porém o efeito direto fenotípico de PUR foi pequeno $(0,3961)$ (Tabela 8). Os coeficientes de trilha fenotípicos explicaram bem as variaçôes em $\mathrm{PC}$, como indica o alto valor de determinação do modelo $\left(\mathrm{R}^{2}=0,9443\right)$ e pelo efeito residual pequeno $(0,2360)$, o que reflete a excelente contribuição das variáveis do modelo para a produção de sacarose.

\section{CONCLUSÃO}

Devido às características agroindustriais superiores, as famílias FA-2, FA-3, FA-5, FA-8 e FA-9 podem ser selecionadas para produção de cana e açúcar. Os resultados relacionados à porcentagem aparente de sólidos solúveis indicaram as famílias FA-4, FA-5, FA-6 e FA-10 com tendência para maturação precoce. Os caracteres $\mathrm{TCH}$ e $\mathrm{TBH}$ foram os que mais contribuíram para a divergência genética entre as famílias. O uso dos pares de famílias mais divergentes FA-3 X FA-4, FA-3 X FA-5, FA-3 X FA-10, FA-4 X FA-9, FA-5 X FA-7, FA-3 X FA-1, FA-9 X FA-10, FA-4 X FA-7, FA-5 X FA-9 e FA-1 X FA-7 podem ser recomendadas para uso no melhoramento com possibilidades de proporcionar novas combinaçôes com êxito na seleção. A seleção de famílias de cana-de-açúcar para elevação da produção de colmos pode ser realizada com base na variável NMC.

\section{REFERÊNCIAS}

ABREU, A.F.B; RAMALHO, M.A.P.; FERREIRA, D.F. Selection potential for seed yield from intra and inter-racial populations in common bean. Euphytica, v.108, p.121-127, 1999.

AMORIM, E.P.; RAMOS, N.P.; UNGARO, M.R.G.; KIIH, T.A.M. Divergência genética em genótipos de girassol. Ciência e Agrotecnologia, v.31, p.1637-1644, 2007.

BARBOSA, M.P.H.; SILVEIRA, L.C.I. Metodologias de seleção, progressos e mudanças no programa de melhoramento genético da cana-de-açúcar da Universidade Federal de Viçosa. STAB, v.18, p.30-32, 2000.

BASTOS, I.T.; BARBOSA, M.H.P.; CRUZ, C.D.; BURNQUIST, W.L.; BRESSIANI, J.A.; SILVA, F.L. Análise dialélica em clones de cana-de-açúcar. Bragantia, v.62, p.199-206, 2003.

BASTOS, I.T.; BARBOSA, M.H.P.; RESENDE, M.D.V.; PERTERNELLI, L.A.; SILVEIRA, L.C.I.; DONDA, L.R.; FORTINATO, A.A.; COSTA, P.M.A.; FIGUEIREDO, I.C.R.Avaliação da interaçáo genótipo x ambiente em cana-de-açúcar via modelos mistos. Pesquisa Agropecuária Tropical, v. 37, p.195-203, 2007. 
CARPENTIERI-PÍPOLO, V.; DESTRO, D.; PRETE, C.E.C.; GONZALES, M.G.N.; POPPER, I.; ZANATTA, S.; SILVA, F.A. DA. Seleçấo de genótipos parentais de acerola com base na divergência genética multivariada. Pesquisa Agropecuária Brasileira, v.35, p.1613-1619, 2000.

CRUZ, C.D. Genes: aplicativo computacional em genética e estatística. Viçosa: UFV, 2007. (Versão 2007.0.0).

CRUZ, C.D.; CARNEIRO, P.C.S. Modelos biométricos aplicados ao melhoramento genético. 2.ed. Viçosa: UFV, 2006. 585p.

CRUZ, C.D.; REGAZZI, A.J. Modelos biométricos aplicados ao melhoramento genético. Viçosa, MG: Imprensa Universitária, 2004. 480p.

DILLEWIJN, C. Botany of sugarcane. Walthen: Chronica Botanica, 1952. p.136-141. 359p.

DUTRA FILHO, J.A.; MELO, L.J.O.T.; RESENDE, L.V.; ANUNCIAÇÃO FILHO, C.J.; BASTOS, G.Q. Aplicação de técnicas multivariadas no estudo da divergência genética em canade-açúcar. Revista Ciência Agronômica, v.42, p.185-192, 2011.

FERNANDES, A. Cálculos na agroindústria da cana-de-açúcar. 2.ed. Piracicaba: EME, 2003. 240p.

FERREIRA, F.M.; BARROS, W.S.; SILVA, F.L.; BARBOSA, M.H.P.; CRUZ, C.D.; BASTOS, I.T. Relaçóes fenotípicas e genotípicas entre componentes de produção em cana-de-açúcar. Bragantia, v.66, p.605-610, 2007.

KOFFLER, N.P.; LIMA, J.F.W.F.; LACERDA, J.F.; SANTANA, J.F.; SILVA, M.A. Caracterização edafo-climática das regiôes canavieiras do Brasil: Pernambuco. Piracicaba: Planalsucar, 1986. 78p.

MAHALANOBIS, P.C. On the generalized distance in statistic. Proceedings of the National Institute of Science, v.2, p.49-55, 1936.

MAMEDE, R.Q.; BASSINELO, A.I.; CASA GRANDE, A.A.; MIOQUE, J.Y.J. Potencial produtivo de clones RB de cana-de-açúcar no município de Nova Europa - SP. STAB, v.20, p.32-35, 2002.

MELO, L.J.O.T.; OLIVEIRA, F.J.; BASTOS, G.Q.; ANUNCIAÇÁO FILHO, C.J.; REIS, O.V. Interaçáo genótipo $x$ ciclos de colheita de cana-de-açúcar da Zona da Mata Norte de Pernambuco. Bragantia, v.65, p.197-205, 2006.

OLIVEIRA, R.A.; RESENDE, M.D.V.; DAROS, E.; BESPALHOK-FILHO, J.C.; ZAMBON, J.L.C.; IDO, O.T.; WEBER, H.S. Genotypic evaluation and selection of sugarcane clones in three environments in the State of Paraná. Crop Breeding and Applied Biotechnology, v.5, p.426-434, 2005.

PEDROZO, C.A.; BARBOSA, M.H.P.; VILELA, M.D.; PETERNELLI, R.L.A.; COSTA, P.M.A.; SILVA, F.L. Eficiência da seleção em fases iniciais do melhoramento da cana-de-açúcar. Revista Ceres, v.55, p.1-8, 2008.
RAMALHO, M.A.P.; SANTOS, J.B.; ZIMMERMANN, M.J.O. Genética quantitativa em plantas autógamas: aplicaçôes ao melhoramento do feijoeiro. Goiânia: UFG, 1993. 271p.

RAO, R.C. Advanced statistical methods in biometric research. New York: J. Wiley, 1952. 390p.

REDDY, C.R.; REDDI, M.V. Degree of genetic determination, correlation and genotypic and phenotypic path analysis of cane and sugar yield in sugarcane. Indian Journal of Genetics and Plant Breeding, v.46, p.550-557, 1986.

SCOTT, A.J.; KNOTT, M.A. A cluster analysis method for grouping means in the analysis of variance. Biometrics, v.30, p.507$512,1974$.

SANTANA, M.S.; OLIVEIRA, F.J.; MELO, L.J.O.T. Correlações genéticas em alguns clones RB e em variedades de cana-de-açúcar. Revista Brasileira de Ciências Agrárias, v.5, p.460-467, 2010.

SILVA, C.M.; GONÇALVES-VIDIGAL, M.C., VIDIGAL FILHO, P.S.; SCAPIM, C.A.; DAROS, E.; SILVÉRIO, L. Genetic diversity among sugarcane clones (Saccharum spp.). Acta Scientiarum Agronomy, v.27, p.315-319, 2005.

SILVA, M.A. Interação genótipo $\mathrm{x}$ ambiente e estabilidade fenotípica de cana-de-açúcar em ciclo de cana de ano. Bragantia, v.67, p.109-117, 2008.

SILVA, F.L.; PEDROZO, C.A.; BARBOSA, M.H.P.; RESENDE, M.D.V.; PETERNELLI, L.A.; COSTA, P.M.A.; VIEIRA, M.A. Análise de trilha para os componentes de produção de cana-deaçúcar via blup. Revista Ceres, v.56, p.308-314, 2009.

SILVA, G.C.; OLIVEIRA, F.J.; ANUNCIAÇÃO FILHO, C.J.; SIMÓES NETO, D.E.; MELO, L.J.O.T. Divergência genética entre genótipos de cana-de-açúcar. Revista Brasileira de Ciências Agrárias, v.6, p.52-58, 2011

SINGH, D. The relative importance of characters affecting genetic divergence. The Indian Journal of Genetics and Plant Breeding, v.41, p.237-245, 1981.

SOKAL, R.R.; MICHENER, D. A statistical method for evaluation systematic relationships. University of Kansas Scientific Bulletin, v.38, p.1409-1438, 1958.

SUKHCHAIN, D.S.; SAINI, G.S. Inter-relationships among cane yield and commercial cane sugar and their component traits in autumn plant crop of sugarcane. Euphytica, v.95, p.109-114, 1997.

VENCOVSKY, R. Herança quantitativa In: PATERNIANI, E.; VIEGAS, G.P. (Ed.). Melhoramento e produção do milho no Brasil. 2.ed. Campinas: Fundação Cargill, 1987. cap. 5, p.137-214.

WRIGHT, S. Correlation and causation. Journal of Agricultural Research, v.20, p.557-585, 1921. 